\title{
Women in physics: A comparison to science, technology, engineering, and math education over four decades
}

\author{
Linda J. Sax, ${ }^{1}$ Kathleen J. Lehman, ${ }^{1}$ Ramón S. Barthelemy, ${ }^{2}$ and Gloria Lim ${ }^{1}$ \\ ${ }^{1}$ Graduate School of Education and Information Studies, University of California Los Angeles, \\ Los Angeles, California 90095, USA \\ ${ }^{2}$ Department of Teacher Education, University of Jyväskylä, 40014 Jyväskylä, Finland
}

(Received 4 February 2015; published 1 August 2016)

\begin{abstract}
[This paper is part of the Focused Collection on Gender in Physics.] The dearth of women in science, technology, engineering, and math (STEM) fields has been lamented by scholars, administrators, policymakers, and the general public for decades, and the STEM gender gap is particularly pronounced in physics. While previous research has demonstrated that this gap is largely attributable to a lack of women pursuing physics in college, prior research reveals little in terms of the characteristics and career interests of women who do plan to major in physics or how these traits have evolved over time. To address these gaps, this study utilized nationwide data on first-time, full-time college students to (1) document national trends in plans to major in physics among women entering college, (2) document the career aspirations of women who intend to major in physics, and (3) explore the characteristics of women who intend to major in physics and how this population has evolved across time. This study found that women's interest in physics has been consistently very low in the past four decades. The most popular career aspiration among women who plan to major in physics is research scientist, although this career aspiration is declining in popularity, while increasing numbers of women say that they are undecided in their career choice. Further, this study identifies a distinctive profile of the average female physics student as compared to women in other STEM fields and women across all majors. Women who plan to pursue a physics major tend to be confident in their math abilities, value college as an opportunity to learn, plan to attend graduate school, and desire to make theoretical contributions to science. However, they are less likely than women in other fields to have a social activist orientation. These findings have important implications for scholars, educators, administrators, and policymakers as they seek to recruit more women into the physics field.
\end{abstract}

DOI: 10.1103/PhysRevPhysEducRes.12.020108

\section{INTRODUCTION}

Women have contributed to the physics community in myriad ways, from Marie Curie's invaluable work on radioactivity to Jocelyn Bell Burnell's discovery of the pulsar. As has been noted by the American Physics Society [1], recruiting women into physics is important, precisely because of the talent they bring to the discipline. Indeed, given that physicists play key roles in essential areas of society, from health care to national defense, it is in the national interest to recruit physicists from the widest talent pool possible.

Despite the demand for more women in physics, women are underrepresented at all levels of the field. Beginning in secondary school, while women represent nearly $47 \%$ of students in high school physics courses, fewer women than men take the most advanced physics courses, representing $41 \%$ of students enrolled

Published by the American Physical Society under the terms of the Creative Commons Attribution 3.0 License. Further distribution of this work must maintain attribution to the author(s) and the published article's title, journal citation, and DOI. in Advanced Placement (AP) Physics B and 32\% of students enrolled in AP Physics C. Further, women in these courses are less likely than men to take and subsequently pass the AP exam [2]. Hence, women are significantly underrepresented in the advanced physics courses that would prepare them to major in physics, and women who do take such courses are less likely to earn college credit for them.

At the undergraduate level, women earned fewer than $20 \%$ of all physics bachelor's degrees in 2012 [3]. While this figure represents progress for women over the last half-century (up from 5\% of physics degrees earned by women in 1966), it also reflects a backslide over the past decade, from a peak of $23 \%$ of undergraduate physics degrees earned by women in 2002. The underrepresentation of women in physics also stands in stark contrast to their representation across science, technology, engineering, and math (STEM) degrees generally, where women in 2012 earned 35\% of bachelor's degrees [4]. Women's pattern of underrepresentation in physics continues at the doctoral level, where they represent $20 \%$ of physics students in doctoral programs and hold $18 \%$ of postdoctoral positions [3]. 
Subsequently, women's representation remains relatively low in academic positions in physics, as they account for approximately $14 \%$ of faculty members [5]. Notably, however, their representation among assistant professors in physics is $17.5 \%$ [1], a figure closer to their representation in doctoral programs. While these data represent a snapshot in time, and therefore do not capture the longitudinal pathways of women in the physics and STEM pipelines, such persistent underrepresentation makes it clear that retaining women at all levels of physics is important, and a renewed focus on recruiting women into physics at the high school and college levels is particularly necessary.

Given that women's participation in physics at the high school and undergraduate levels is pivotal to addressing women's overall underrepresentation in the field, it is important that scholars, administrators, and policymakers understand what makes some women more likely than others to pursue the physics major in college. Little is known about the characteristics and career goals of women who may be most attracted to physics. Further, there is limited understanding of how the talent pool of women pursuing physics has evolved over time; does the field attract the same types of women today as it has in the past?

To address these gaps, this study uses nationwide data on entering college students to (1) document nationwide trends in aspirations to major in physics among women entering college, (2) document the career aspirations of women who plan to major in physics, and (3) explore the characteristics of women who choose to major in physics and how this population has evolved over time.

\section{LITERATURE REVIEW}

While there is expansive literature documenting women's underrepresentation in STEM fields, there is comparably less research exploring women's experiences and challenges in physics. Consequently, it is necessary to look at literature in both physics education and broader STEM education to consider possible reasons for women's underrepresentation in the field. To guide this conversation, this review will consider five categories identified by Kanny, Sax, and Riggers-Piehl [6] as the most prevalent themes in the literature on the gender gap in STEM: background characteristics, familial expectations and beliefs, K-12 experiences, psychological factors, and perceptions of the field. First, we will briefly summarize what is known with respect to each of these categories about women's interest in STEM fields in general. Then, we will turn to a discussion of what is known about women's interest in physics, specifically. This review includes a broad range of factors relevant to women's pursuit of STEM, many of which could not be addressed in this study; however, they are included here in order to place the study of women in physics into the larger context of women in STEM.

\section{A. Explanations for the gender gap in STEM}

\section{Background characteristics}

Much of the literature on women in STEM has considered the role of women's background traits, such as one's race or ethnicity and socioeconomic status, in predicting women's interest in pursuing a STEM field. In particular, African-American, Latina, Native American women, and those from lower socioeconomic backgrounds are underrepresented in STEM disciplines [7,8]. Asian women are the only demographic group that is overrepresented in the STEM fields, relative to their representation in the general population [9]. Still, even Asian-American women face barriers in STEM, particularly at later career stages, as they are the group with the lowest representation in tenured faculty positions [10]. Ong et al. [9] argue that women of color are underrepresented in STEM not because they are less interested in STEM fields than their white peers but because of a complex web of factors relating to educational inequities that women of color face in the STEM fields.

\section{Familial expectations and beliefs}

Previous studies have identified various factors stemming from women's family experiences that affect their interest in STEM fields. Specifically, some studies have found that factors like parents' occupations play a role in whether or not female students will be interested in earning a STEM degree $[11,12]$. Additionally, the degree to which parents encourage their children to pursue a STEM field as well as provide access to STEM-related learning experiences is also important to girls' interest in STEM $[13,14]$. Other work has focused on the influence that parental behaviors and beliefs about their daughters' abilities to perform and succeed in a STEM field have on girls' plans to pursue STEM $[15,16]$. For example, parents often have a direct influence on their children's tracking placement in coursework, such as math and science [17]. This, in turn, affects girls' level of preparation to pursue more advanced math and science coursework and, eventually, a STEM major in college.

\section{3. $\mathrm{K}-12$ experiences}

Students' K-12 experiences have been shown to have an impact on their decision to pursue a STEM field in college. Differences in men's and women's academic preparation for STEM coursework in college stems from differences in their K-12 experiences. For instance, as discussed earlier, women tend to take fewer advanced math and physics courses in high school, which leaves them less prepared than men to pursue STEM majors in college [18]. Further, studies have shown that structural barriers, including

\footnotetext{
${ }^{1}$ Asian women are not overrepresented in all STEM subfields (e.g., they have low representation in Earth and atmospheric sciences [4]).
} 
negative classroom experiences, exist in the K-12 environment that can dissuade girls from pursuing their interest in STEM disciplines [19,20]. For instance, the effect of participation in elementary school performance-based science activities varies by gender, such that girls showed a decrease in their self-rated science abilities, even though they participated equally in the leadership aspects of the science activities and there was no real difference in girls' and boys' performance (as measured by grades). Hence, even when girls participate in classroom activities known to increase girls' interest in STEM fields, it may still not be enough to overcome many girls' beliefs that STEM fields are best suited for boys [21].

\section{Psychological factors}

Numerous studies have found that various psychological factors are related to women's participation in STEM fields. More specifically, women have been found to have lower self-confidence and/or self-concepts of their math and science abilities [22,23,24]. Further, women who report high levels of math self-concept are more likely to report STEM-related career goals [25] while women who report experiencing math anxiety are less likely to be interested in STEM occupations [26].

Certain personality traits are important to women's interest in STEM fields. Women tend to be more service oriented than men in their choice of career. For instance, college women report stronger social activist values than do men, which is negatively associated with interest in a STEM major [27]. As will be discussed more below, interest in service- and people-oriented careers, combined with a perception that STEM fields present limited opportunities to help others, dissuade many women from pursuing a STEM field. Further, within STEM fields, women who are attracted to a STEM discipline tend to be drawn to fields such as the biological sciences, where opportunities to help others are more explicit $[28,29]$.

\section{Perceptions of the field}

Other aspects of women's perceptions of STEM fields are also integral to whether or not they pursue a STEM major and/or career. In particular, the extent to which women and girls believe a STEM field will be welcoming impacts their intentions to pursue that field. For example, the belief that certain STEM fields are best suited for "nerds" or "geeks" may prohibit some women from pursuing them, despite their own interests or inclinations [30]. Stereotypes play a particularly important role when it comes to individuals who may serve as role models for young women. Research has found that women who interact with role models in STEM careers who do not fit into stereotypes are more likely to believe they can succeed in a STEM career than women who had role models that fit into stereotypes [31]. Additionally, the extent to which women perceive a field to be supportive of their other values, such as family or interpersonal orientations, may also play a role in their participation in STEM disciplines [18]. In fact, several studies have found that an incongruence between women's goals, particularly communal goals (e.g., working with people or helping others), and the perception that STEM careers impede these goals disproportionally and negatively affect women's decision to pursue STEM careers $[32,33]$.

\section{B. Gender and interest in physics}

Although there is a scarcity of studies that consider the gender gap in physics, much of the literature that does exist suggests that women's high school experiences are particularly important for their interest in physics in college $[34,35,36,37,38]$. For instance, developing an identity around physics in high school is key, as Hazari et al. [35] found that students' sense of their physics identity in high school predicted choosing a physics major in college. In the high school setting, one of the few predictors found to impact women's physics identity was discussing their underrepresentation in physics when in high school [35].

High school experiences in physics also relate to women's academic success in the field. Sadler and Tai [37] showed that certain high school predictors impacted students' grades in introductory college physics. Although gender was not a significant predictor, the type of physics class that students took did have an impact on students' grade in physics in college. Students who took regular high school physics saw only modest impacts on their college grade; however, those who took at least two years of high school physics or advanced courses saw much stronger physics grades in college. Consequently, women's lower representation in AP physics disadvantages their future success in college physics. In their study, pedagogy was also critical; high school classes with greater emphasis on conceptual understanding and deeper treatments of fewer topics predicted higher college grades (though the study did not differentiate on the effect of pedagogy specifically for women students).

Carlone [34] used a qualitative lens to understand women's experiences in high school physics. Through site visits and observations, she found that high school girls not only had success in the classroom, but took on the prototypical view of physics (i.e., that science is authoritative and students are "dutiful"). However, she found that their motivation to succeed was a function of their overall achievement orientation, not necessarily their interest in physics per se.

\section{THEORETICAL FRAMEWORK}

The abovementioned categories of factors relevant to the gender gap in STEM in general, and physics in particular, emerge from a review of the empirical literature on the 
topic. However, all these factors are not necessarily addressed in any one study. Therefore, this study will rely on social cognitive career theory (SCCT) as a means of bringing multiple pertinent factors together, although not all categories found to be relevant in the extant literature map onto the SCCT framework. Much of the literature on the selection of STEM majors and careers considers this decision-making process through the lens of SCCT [39]. SCCT provides an appropriate framework to study how multiple components collectively lead to career-related choices in a life-long temporal process (see Fig. 1), and can be applied to the pursuit of the physics major. SCCT's Model of Career-Related Choice Behavior (MCRCB) suggests that personal characteristics, background contexts, and learning experiences work together to affect a person's self-efficacy, or one's perceived ability to perform successfully in a given context, and outcome expectations. Individuals consider their sense of self-efficacy and ultimately shape their outcome expectations to pursue interests in areas they feel they can succeed. A person's contextual influences (i.e., their current contexts) moderate which interests one ultimately pursues (choice goals and actions).

SCCT is a helpful framework for studying the determinants of women's choice to pursue a STEM field, such as physics, during college. Previous research has demonstrated that SCCT is effective in predicting students' STEM career outcomes [40]. Given this, SCCT provides guidance in this study's consideration of the many different factors that work together to influence women's decision to major in physics.

\section{OBJECTIVES}

Kanny, Sax, and Riggers-Piehl [6] conclude their review of 40 years of research on gender and STEM by arguing that despite the wealth of knowledge on why women do or do not pursue STEM majors, surprisingly little is known about women's reasons for choosing specific STEM majors (such as physics). Further, there is virtually no data that speak to how the population of women interested in physics may have changed over time.

Hence, this study examines how the gender gap in undergraduate women's intention to major in physics has changed in the past four decades. In addition, the study explores how women's interest in physics and their career aspirations have evolved across time and compare to women in other STEM fields, specifically, chemistry, biological sciences, computer science, mathematics or statistics, as well as with all college women in the aggregate. By exploring these trends related to women's participation in physics, as well as determinants of women's interest in physics, this study will inform educators, administrators, and policymakers and help bolster their efforts to increase women's participation in physics. Specifically, this study utilizes nationwide data on incoming college students collected over the past four decades to address the following research questions:

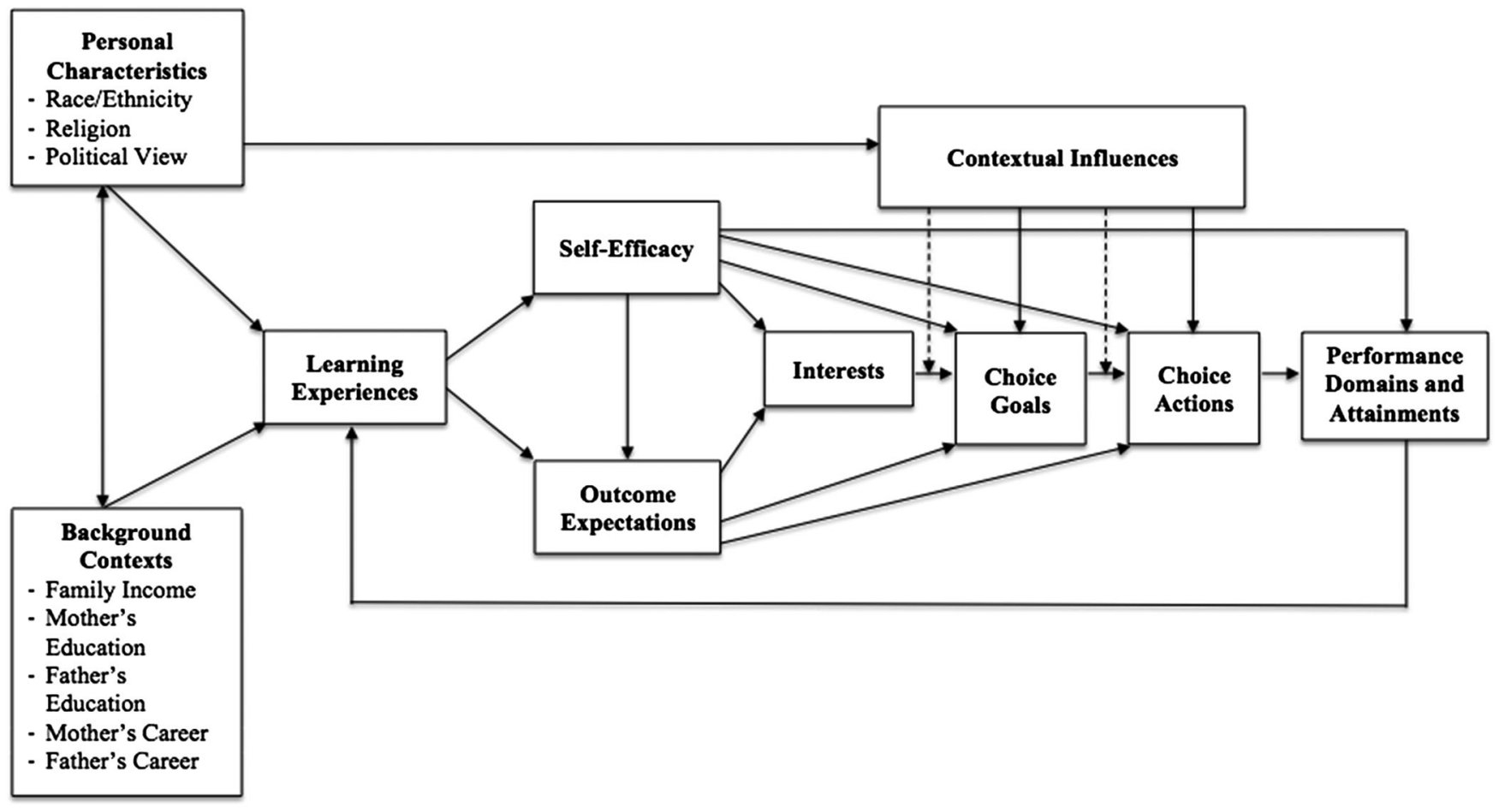

FIG. 1. SCCT adapted from Lent et al. [39]. 
(1) How has incoming college women's intent to major in physics changed over the past four decades compared to women's intent to major in other STEM fields, such as chemistry, biological sciences, computer science, and mathematics or statistics?

(2) What are the most popular intended career choices of women physics majors? How have the career aspirations of women who plan to major in physics changed over the past four decades relative to women from other fields?

(3) What individual characteristics correlate with women's decision to major in physics versus all other fields and versus all other STEM fields? To what extent have these characteristics and/or their salience changed over time?

In our analysis we specifically focus on the diverse experiences of women students without comparison to men. Instead, we compare women in physics to women pursuing other STEM fields. Previous research in physics education has often explored gender issues by comparing women to men; however, many scholars have argued that this kind of work is problematic because it presumes that men are the standard that women must be compared against. It also lacks a focus on the unique lived experiences of women. For a full literature review exploring the issue of comparing women to men in physics, and why this should be avoided, see Traxler et al. [41]. Examples of qualitative research moving past gap analysis have also begun to appear within the literature $[42,43,44,45]$.

\section{METHODS}

\section{A. Data source and sample}

Data used for this study come from the Cooperative Institutional Research Program (CIRP) Freshman Survey. The oldest and largest longitudinal study of American higher education, the CIRP Freshman Survey is administered annually to first-year college students and collects information on a wide range of topics, including demographic background, high school experiences, college expectations, self-concepts, values, and life goals, as well as academic and career aspirations.

This study is based on CIRP data from over 1200 baccalaureate-granting institutions from 1971 to 2013. The first analysis (research question 1) explores how women's intent to major in physics ${ }^{2}$ has fluctuated over time and is based on a sample of 4577098 female respondents across the four decades. The second analysis (research question 2) explores the career aspirations of women who intend to major in physics and is based on the

\footnotetext{
${ }^{2}$ Physics majors are defined as those who intend to major in "physics" and do not include those planning to major in other physical sciences such as chemistry or astronomy.
}

responses of 4375369 women who completed the survey between 1971 and 2011. ${ }^{3}$ Both samples are weighted by institutional control (public versus private), type (four-year college versus university), and selectivity so that they better reflect the population of first-time, full-time college students at all four-year institutions in the United States for each year. The weights are designed to compensate for under- or overrepresentation of students from different types of colleges and universities (see Pryor et al. [46] for a weighting scheme, in addition to validity, and reliability).

The regression analysis (research question 3) provides insight into the relationship of key variables (described below) to women's selection of the physics major, and focuses on five specific cohorts-those entering college in 1976, 1986, 1996, 2006, or 2011. The five years included in the regressions were selected because they represent the most comprehensive set of core survey items available at regular intervals. The two regression samples are unweighted and are composed of (1) 399766 female students from across all majors (including 1118 female students intending to major in physics) and (2) 65993 female students who planned to major in any of the STEM fields (including 1118 female physics majors).

\section{B. Data analysis}

Research question 1 examines how incoming female students' intent to major in physics has changed since 1971 in comparison to their interest in other STEM majors. To address this question, the proportions of women who reported plans to major in physics on the Freshman Survey were examined from 1971 to 2013. In order to infer differences in major aspirations among the STEM subfields, one-sample $z$-tests were performed to compare the differences between the proportions of women who intend to major in physics with that of each subfield.

Research question 2 examines the career aspirations of women who intend to major in physics and how these aspirations have changed over time. Through crosstabulations, we identify top career choices (from a list of 24 careers) that were selected by women intending to major in different STEM fields (and all fields combined) in 2011. The proportion of women selecting a specific career choice in each subfield was calculated, and two-sample $z$-tests were performed to test the differences in the proportions selecting each career field between women who intend to major in physics and women who intend to major in other subfields within STEM. We also examined trends in career choice for female physics majors to see if any notable shifts have occurred since 1971.

\footnotetext{
${ }^{3}$ For some analyses, 2011 is the latest time point available due to (a) the nature of the raw data available to the research team or (b) the fact that career categories after 2011 are not comparable to earlier years.
} 
Research question 3 examines the characteristics associated with women's selection of a physics major and explores if these characteristics and/or their predictive power have changed over time. Using the five-year data set (i.e., 1976, 1986, 1996, 2006, and 2011), logistic regression analyses were conducted for the female sample in two ways: (1) to explore the likelihood of majoring in physics (versus all other majors) and (2) to explore the likelihood of majoring in physics (versus all other STEM majors). Logistic regression analysis reveals how the "odds" of a certain outcome (e.g., majoring in physics) are statistically predicted by independent variables.

Independent variables were chosen based on the MCRCB [39]. They were placed into temporally sequenced blocks ${ }^{4}$ to best understand predictors of intent to major in physics. A series of correlations and factor analyses were conducted to narrow the list of variables to those that were most conceptually and statistically of interest in understanding how students select majors. Only the common variables that were asked across all of the five years (1976, 1986, 1996, 2006, 2011) were included in this analysis. To specify the factors, we used principal axis factoring with promax rotation. This process was performed first for the entire regression data set (five years combined), and then the strength of the factors was further verified for each of the five years. The threshold for reliability was set $^{5}$ at a Cronbach's alpha of 0.60 , and variables were only considered valid for inclusion in a factor if they loaded at 0.40 or higher (ultimately, all loadings exceeded 0.60). In all, seven factors were created (see Appendix B).

Drawn from the CIRP Freshman Survey, the final set of 41 variables was categorized into eight blocks. The blocks included personal characteristics, background contexts, learning experiences, self-efficacy (e.g., mathematics ability), outcome expectations (e.g., expectations of changing one's major), interests, contextual influences (e.g., financial concern for college), and choice goals (e.g., degree aspirations). Regression models also include a time variable to account for changes across the years. (See Appendixes A and B for a list of variables and factors.)

These 41 variables were included in both regression analyses (physics versus all and physics versus other STEM) to determine which variables were statistically significant $(p<0.01)$ across all years combined. Variables that were not significant for either model were removed. Then, the logistic regression was run again with the remaining variables, using identical models for the all-women sample and the STEM-only sample. Finally, time-variable interaction terms were added to identify the

\footnotetext{
${ }^{4}$ Blocks were determined by selecting the variables available in our data set that best reflected the elements of SCCT.

${ }^{5}$ We included some factors that fell just below this threshold due to prior usage in several major studies $[47,48]$.
}

TABLE I. Percentage of women intending to major in STEM fields, selected years. Note that in all years the proportion of women intending to major in physics is significantly different from the proportion selecting each of the other STEM majors.

\begin{tabular}{lccccr}
\hline \hline & 1971 & 1981 & 1991 & 2001 & 2011 \\
\hline Physics & 0.2 & 0.1 & 0.2 & 0.2 & 0.2 \\
Biological sciences & 3.8 & 4.1 & 5.8 & 7.9 & 12.4 \\
Computer science & 0.8 & 5.0 & 1.5 & 1.5 & 0.5 \\
Engineering & 0.3 & 3.5 & 3.7 & 3.0 & 4.2 \\
Math or stats & 3.9 & 1.0 & 0.8 & 0.6 & 0.8 \\
Chemistry & 0.6 & 0.7 & 0.7 & 0.8 & 1.2 \\
\hline \hline
\end{tabular}

possible changing salience of each variable. These terms were included last in order to directly compare full models with and without the interaction terms. Statistically significant interaction terms indicate that an independent variable has become a stronger or weaker predictor over time.

\section{RESULTS}

\section{A. Question 1: Women's interest in the physics major}

Table I displays women's intent to major in particular STEM majors in our chosen time intervals. At each time point women's interest in physics is significantly lower than their interest in other STEM majors. Strikingly, women's interest in majoring in physics remains constant over the four-decade period at $0.2 \%$ in all years except 1981 . The stable trend in physics is quite different than the trends observed in other majors. For biology, engineering, and chemistry women's interest has increased over this period. Women's interest in math, on the other hand, has steadily decreased over time from $3.9 \%$ in 1971 to $0.8 \%$ in 2011 . For computer science, women's interest has fluctuated significantly over time, reaching as high as 5\% in 1981 and then decreasing to $0.5 \%$ in 2011 . Figure 2 represents these data graphically over the full span of four decades.

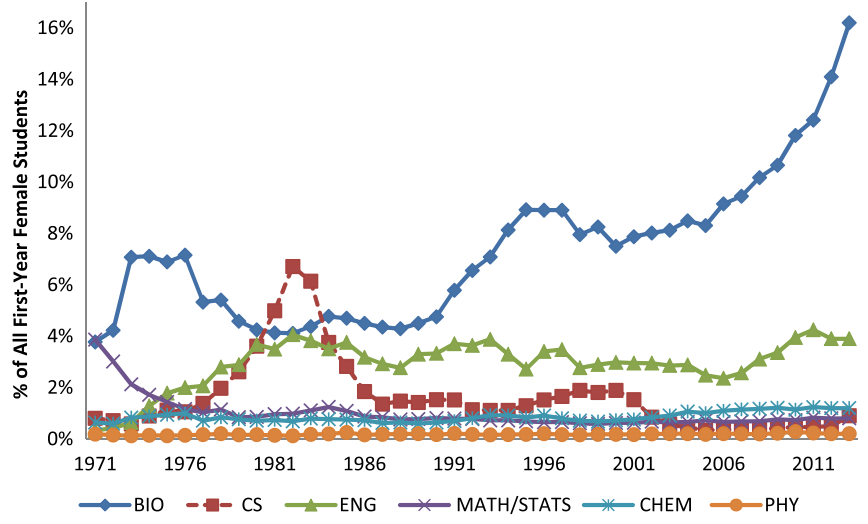

FIG. 2. The proportion of all first-year, female students who reported intention to major in a STEM fields from 1971 to 2013. 
TABLE II. Most popular career choices of first-year female STEM majors in 2011. Note that the superscripts next to the percent of career for physics indicate the fields ( $\mathrm{B}=$ biological sciences; $\mathrm{CS}=$ computer science; $\mathrm{E}=$ engineering; $\mathrm{CH}=$ chemistry) that were significantly different from physics majors in the career aspiration among women. Percentages in bold indicate careers selected by at least $1 \%$ of female students in the major. The choices of "other," "Interpreter," and "Statistician" are excluded from this list.

\begin{tabular}{|c|c|c|c|c|c|c|c|c|}
\hline Aspiring career & PHY (\%) & & Bio $(\%)$ & CS $(\%)$ & ENG $(\%)$ & Math (\%) & Chem $(\%)$ & All women $(\%)$ \\
\hline Research scientist & 31.2 & $\mathrm{~B}, \mathrm{CS}, \mathrm{E}, \mathrm{M}, \mathrm{CH}$ & 12.3 & 0.4 & 1.6 & 2.8 & 16.6 & 2.4 \\
\hline Undecided & 23.3 & B, CS, E, CH & 12.8 & 11.3 & 6.4 & 26.1 & 12.1 & 16.6 \\
\hline Engineer & 12.3 & $\mathrm{~B}, \mathrm{CS}, \mathbf{E}, \mathrm{M}, \mathrm{CH}$ & 0.5 & 4.6 & 76.7 & 2.8 & 1.6 & 3.5 \\
\hline Physician & 7.1 & $\mathrm{~B}, \mathrm{CS}, \mathrm{E}, \mathrm{M}, \mathrm{CH}$ & 35.1 & 1.0 & 4.0 & 3.8 & 21.8 & 9.3 \\
\hline College teacher & 3.7 & $\mathrm{~B}, \mathrm{CS}, \mathrm{E}, \mathbf{C H}$ & 0.2 & 0.1 & 0.1 & 4.4 & 0.6 & 0.4 \\
\hline Military & 3.7 & $\mathrm{~B}, \mathrm{CS}, \mathrm{E}, \mathrm{M}, \mathrm{CH}$ & 0.3 & 0.9 & 2.1 & 1.6 & 1.1 & 0.5 \\
\hline K-12 education & 3.0 & B, CS, E, M & 1.0 & 0.2 & 0.2 & 21.3 & 2.1 & 9.0 \\
\hline Architect & 2.3 & $\mathrm{~B}, \mathrm{CS}, \mathrm{E}, \mathrm{M}, \mathrm{CH}$ & 0.1 & 0.2 & 0.6 & 0.6 & 0.0 & 0.6 \\
\hline Nursing & 2.1 & B, CS, E, CH & 18.4 & 0.0 & 0.7 & 1.7 & 0.3 & 18.6 \\
\hline Artist & 0.9 & & 0.5 & 1.6 & 0.4 & 0.4 & 0.5 & 7.3 \\
\hline Business & 0.7 & $\mathrm{CS}, \mathrm{M}$ & 0.6 & 2.9 & 1.2 & 22.9 & 0.5 & 9.4 \\
\hline Social worker & 0.7 & $\mathrm{~B}, \mathrm{CS}, \mathrm{E}, \mathrm{M}, \mathrm{CH}$ & 0.2 & 0.0 & 0.0 & 0.1 & 0.0 & 1.9 \\
\hline Computer programmer & 0.4 & B, CS, E, CH & 0.0 & 68.6 & 2.6 & 1.1 & 0.0 & 0.5 \\
\hline Lawyer & 0.2 & M & 0.5 & 0.1 & 0.7 & 1.7 & 1.1 & 3.6 \\
\hline Government & 0.1 & & 0.4 & 0.5 & 0.1 & 0.6 & 0.1 & 1.8 \\
\hline Farmer or forester & 0.0 & B & 2.0 & 0.0 & 0.1 & 0.0 & 0.0 & 0.4 \\
\hline Psychologist (clinical) & 0.0 & & 0.3 & 0.0 & 0.0 & 0.0 & 0.3 & 2.1 \\
\hline
\end{tabular}

\section{B. Question 2: Career plans for female physics majors}

Next, we examine the career aspirations among female first-year college students who intend to major in physics. Table II reveals the top career choices of females in the physics major in 2011 and shows how these career aspirations compare with those of women majoring in other STEM fields and all fields combined. The most popular career choice for female physics majors is research scientist, selected by nearly one-third of this group. Becoming a research scientist is not only the most popular career choice among women physics majors, but it is a much more common choice for women in physics than for women in any other STEM field. Despite this, the overall popularity of research careers among female physics majors has actually declined over time from a high of $57.4 \%$ in 1971 to $31.2 \%$ in 2011 . Alternatively, the "undecided" career has gained significant traction, growing from $8.0 \%$ to $23.3 \%$ during this time frame (see Fig. 3). (Notably, the proportion of female students with undecided career plans has risen faster in physics than in any other STEM field; in fact, in some STEM fields-biological sciences and math-the proportion of women who are undecided is actually lower today than in 1971.) Other popular career choices for female physics majors include engineering (12.3\%), medicine $(7.1 \%)$, and, to a lesser extent, college teaching $(3.7 \%)$, the military $(3.7 \%)$, and K-12 education $(3.0 \%)$. Interest in these careers has fluctuated somewhat over time (specifically, increased interest in engineering and declining interest in K-12 education), but the changes over time are quite small.
Table II also reveals that some STEM majors are more diffuse in their career aspirations than others. Among female physics majors, for example, the most popular career (research scientist) is indicated by only $31.2 \%$ of students. In computer science and engineering, on the other hand, career goals are more concentrated on the specific profession associated with that major, with $76.7 \%$ of female engineering majors planning to become engineers and $68.6 \%$ of female computer science majors planning to become computer programmers. Careers in medicine were favored by female students in biology and chemistry with a representation of $35.1 \%$ and $21.8 \%$ of students, respectively. Nursing was also a popular career choice for $18.4 \%$ of female biology majors, which was equivalent to the interest level for women overall, but far higher than for all other STEM majors. Careers in law, government, and business attract few female STEM majors, although

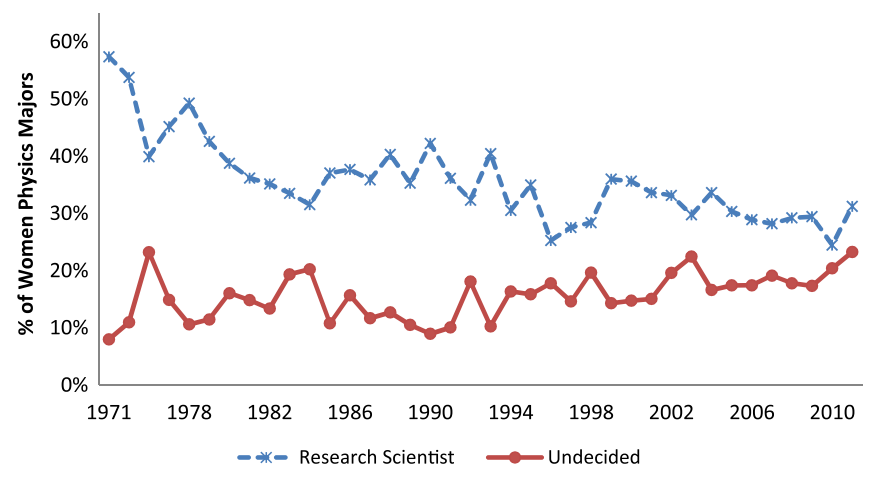

FIG. 3. The shifting career choices of female aspiring physics majors from 1971 to 2011. 
business was a popular career choice for women majoring in mathematics $(22.9 \%)$.

\section{Question 3: Characteristics associated with majoring in physics}

Now we turn to the results of the logistic regression analyses, which examine the student characteristics that are associated with women's decision to major in physics - first, relative to majoring in any other fields, and, second, relative to majoring in any other STEM field. Of the 41 variables included in the initial regression, 40 emerged as significant $(p<0.01)$ for the all-major model and 37 for the STEMonly model. The variables that were significant in the initial regression were then included in the final logistic regression models. To clarify, logistic regression coefficients signify whether the relationship between an independent variable and a dependent variable (i.e., choice of physics major) is positive or negative, and give some indication as to the strength of that relationship. Logistic regression coefficients are similar to linear regression coefficients in that those above zero reflect positive relationships, while those below zero signify negative relationships. Odds ratios $[\operatorname{Exp}(\mathrm{B})]$, by contrast, are centered around 1 . An odds ratio greater than 1 tells us that higher scores on an independent variable increase the odds that the outcome (i.e., choice of physics major) will occur, whereas an odds ratio below 1 suggests that higher scores on an independent variable decrease the odds that the outcome will occur. In the results that follow, independent variables that are significantly associated with the selection of a physics major are sometimes described as "predictors"; the use of predicting is intended to reflect statistical prediction only since causality cannot be known.

\section{Majoring in physics versus any other field}

What predicts women's decision to major in physics versus all other fields? Table III displays the results in terms of two models: model 1, which represents the main effects of independent variables across all years combined, and model 2, which reflects the main effects of independent variables in the base year 1976, along with interaction terms to indicate shifts over time in the predictive power of independent variables. For clarity, a significant positive interaction term denotes a positive effect that has grown stronger with time or a negative effect that has weakened over time. Conversely, a significant negative interaction term indicates a positive effect that have grown weaker over time or a negative effect that has strengthened with time. ${ }^{6}$

\footnotetext{
${ }^{6}$ Interpretation of significant interaction terms thus requires observing the sign (positive or negative) of both main effects and interaction terms. For example, in the interaction described below for student-faculty ratios, the main effect in model 1 is negative $(b=-0.051)$ and the interaction term in model 2 is negative $(b=-0.039)$, suggesting a negative main effect that has become stronger (i.e., more negative) over time.
}

As shown in Table III, a total of 13 variables significantly predict the decision to major in physics versus any other major, most of which have remained stable predictors over time. These include the positive and stable effects of some variables with a particular relevance to science, such as self-rated math ability and desiring to make a theoretical contribution to science. In other words, women who enter college with more positive mathematical self-concepts and who desire to advance science are more likely to major in physics than in other fields combined. Other stable and positive effects include identifying with no religious affiliation, desiring to develop a meaningful philosophy of life, attending college for educational reasons, and aspiring to either master's or Ph.D. degrees (as opposed to stopping after completion of the bachelor's degree). Interestingly, expecting to change one's major field is also a stable positive predictor of majoring in physics, suggesting there is a particular instability of physics as an intended field of study among women. Perhaps this is connected to the growing number of physics majors who are undecided about their career choice.

Some variables emerge as negative predictors that have been stable over time. The first is being Asian or AsianAmerican, revealing that female Asian or Asian-American students have been consistently less likely to major in physics than in other fields. This finding is interesting since Asian-American students tend to be more represented in STEM than other fields, as discussed earlier; apparently this is not the case among women in physics. Female students who espouse more social activist goals are also less likely to major in physics; this is consistent with prior research on women's career values and perceptions of the social good of STEM career choices. In addition, women who place more value on status goals and who have extrinsic motivations for college attendance (i.e., to get a better job or make more money) are also less likely to select a physics major.

Only two variables represent forces that have changed in salience over time. The first is the negative effect of attending institutions with larger student-faculty ratios, which has become more salient over time. In other words, colleges with larger enrollments are increasingly less likely to attract physics majors. Second, attending public institutions, though not significant in the main effects model, is shown to have become a more positive predictor of majoring in physics over time. Further analysis reveals that in 1971 public institutions were slightly less likely to attract female physics majors, and this negative relationship has reversed itself over time, though not enough to generate a statistically significant result in 2011.

\section{Majoring in physics versus other STEM fields}

The above section reveals factors that predict women's interest in physics versus all other fields. One might reasonably question whether the characteristics leading 
TABLE III. Logistic regression predicting choice of physics major among women $(n=399766)$ (compared to all other majors). Bold indicates $p<0.01$. Number of physics majors included in this analysis is 1118 .

\begin{tabular}{|c|c|c|c|c|c|c|}
\hline \multirow[b]{2}{*}{ Variables } & \multicolumn{3}{|c|}{ Main effects model } & \multicolumn{3}{|c|}{ Conditional effects model } \\
\hline & $b$ & SE & $\operatorname{Exp}(B)$ & $b$ & SE & $\operatorname{Exp}(B)$ \\
\hline Year (continuous) & -0.014 & 0.033 & 0.986 & 0.211 & 0.432 & 1.235 \\
\hline \multicolumn{7}{|c|}{ Personal inputs } \\
\hline \multicolumn{7}{|l|}{ Religion (versus Protestant) } \\
\hline Catholic & -0.044 & 0.083 & 0.957 & -0.164 & 0.226 & 0.849 \\
\hline Jewish & -0.298 & 0.173 & 0.742 & -0.981 & 0.485 & 0.375 \\
\hline Other & 0.262 & 0.119 & 1.300 & 0.381 & 0.335 & 1.464 \\
\hline No Religion & 0.254 & 0.086 & 1.289 & 0.390 & 0.241 & 1.477 \\
\hline \multicolumn{7}{|c|}{ Race (versus White) } \\
\hline Other or multi & 0.137 & 0.117 & 1.147 & -0.067 & 0.436 & 0.935 \\
\hline Asian or Pacific Islander & -0.444 & 0.131 & 0.642 & -0.006 & 0.425 & 0.994 \\
\hline Black & -0.100 & 0.207 & 0.905 & -0.046 & 0.550 & 0.955 \\
\hline Latino or Latina & -0.090 & 0.220 & 0.913 & 0.164 & 0.829 & 1.178 \\
\hline Political views & -0.050 & 0.043 & 0.951 & -0.283 & 0.120 & 0.754 \\
\hline \multicolumn{7}{|c|}{ Background characteristics } \\
\hline Father's education & 0.035 & 0.022 & 1.036 & 0.047 & 0.057 & 1.048 \\
\hline Mother's education & -0.008 & 0.022 & 0.992 & -0.079 & 0.060 & 0.924 \\
\hline Family income & -0.033 & 0.027 & 0.967 & 0.091 & 0.077 & 1.095 \\
\hline Father's career: STEM & 0.118 & 0.073 & 1.125 & 0.116 & 0.207 & 1.123 \\
\hline Mother's career: STEM & 0.146 & 0.085 & 1.157 & 0.125 & 0.262 & 1.134 \\
\hline \multicolumn{7}{|c|}{ Learning experiences } \\
\hline High school GPA & 0.077 & 0.033 & 1.081 & 0.105 & 0.088 & 1.110 \\
\hline \multicolumn{7}{|c|}{ Self-efficacy } \\
\hline Self-rating: Math ability & 0.923 & 0.045 & 2.517 & 0.776 & 0.125 & 2.173 \\
\hline Leader (factor) & & & Not sigr & in step 0 & & \\
\hline Scholar (factor) & -0.024 & 0.041 & 0.976 & 0.066 & 0.116 & 1.068 \\
\hline \multicolumn{7}{|c|}{ Outcome expectations } \\
\hline Future act: Change major field & 0.325 & 0.037 & 1.385 & 0.462 & 0.102 & 1.587 \\
\hline Future act: Make at least a ' $\mathrm{B}$ ' average & -0.018 & 0.063 & 0.982 & -0.185 & 0.175 & 0.831 \\
\hline \multicolumn{7}{|c|}{ Interests } \\
\hline Goal: Meaningful philosophy & 0.101 & 0.036 & 1.106 & 0.097 & 0.103 & 1.101 \\
\hline Goal: Theoretical scientific contrib. & 1.275 & 0.036 & 3.578 & 1.446 & 0.103 & 4.246 \\
\hline Goal: Raising a family & -0.077 & 0.033 & 0.926 & -0.007 & 0.091 & 0.993 \\
\hline Social activist (factor) & -0.472 & 0.039 & 0.624 & -0.431 & 0.111 & 0.650 \\
\hline Artistic (factor) & 0.060 & 0.035 & 1.062 & -0.032 & 0.098 & 0.969 \\
\hline Status striver (factor) & -0.436 & 0.039 & 0.647 & -0.299 & 0.113 & 0.742 \\
\hline Educ. reasons for college (factor) & 0.110 & 0.042 & 1.116 & 0.108 & 0.118 & 1.114 \\
\hline Extrins. reasons for college (factor) & -0.118 & 0.030 & 0.889 & -0.167 & 0.085 & 0.846 \\
\hline \multicolumn{7}{|c|}{ Contextual influences proximal to choice behavior } \\
\hline Distance of institution from home & 0.053 & 0.027 & 1.054 & -0.055 & 0.071 & 0.946 \\
\hline Number of institutions applied to & 0.030 & 0.014 & 1.031 & 0.073 & 0.045 & 1.076 \\
\hline Financial concern for college & -0.087 & 0.052 & 0.917 & 0.057 & 0.140 & 1.058 \\
\hline Student-to-faculty ratio & -0.051 & 0.010 & 0.950 & 0.059 & 0.027 & 1.061 \\
\hline Institutional type: University & -0.186 & 0.112 & 0.830 & -0.308 & 0.289 & 0.735 \\
\hline Institutional type: Religious & 0.018 & 0.132 & 1.018 & -0.148 & 0.351 & 0.863 \\
\hline Institutional type: HBCU & -0.747 & 0.424 & 0.474 & -0.576 & 1.020 & 0.562 \\
\hline Institutional control: Public & -0.023 & 0.114 & 0.978 & -0.778 & 0.304 & 0.460 \\
\hline \multicolumn{7}{|c|}{ Choice goals } \\
\hline Ph.D. & 1.118 & 0.129 & 3.059 & 1.493 & 0.322 & 4.452 \\
\hline Law degree & 0.186 & 0.286 & 1.204 & -0.435 & 0.870 & 0.647 \\
\hline
\end{tabular}


TABLE III. (Continued)

\begin{tabular}{|c|c|c|c|c|c|c|}
\hline \multirow[b]{2}{*}{ Variables } & \multicolumn{3}{|c|}{ Main effects model } & \multicolumn{3}{|c|}{ Conditional effects model } \\
\hline & $b$ & SE & $\operatorname{Exp}(B)$ & $b$ & SE & $\operatorname{Exp}(B)$ \\
\hline Medical degree & -0.404 & 0.159 & 0.668 & -0.100 & 0.406 & 0.905 \\
\hline Master's degree or M.Div. & 0.592 & 0.127 & 1.808 & 0.418 & 0.318 & 1.519 \\
\hline \multicolumn{7}{|c|}{ Interaction terms } \\
\hline Catholic $\times$ time & & & & 0.037 & 0.075 & 1.037 \\
\hline Jewish $\times$ time & & & & 0.222 & 0.153 & 1.248 \\
\hline Other $\times$ time & & & & -0.052 & 0.115 & 0.949 \\
\hline No religion $\times$ time & & & & -0.055 & 0.078 & 0.947 \\
\hline Other or multi $\times$ time & & & & 0.064 & 0.128 & 1.066 \\
\hline Asian or Pacific Islander $\times$ time & & & & -0.139 & 0.132 & 0.870 \\
\hline Black $\times$ time & & & & -0.028 & 0.184 & 0.973 \\
\hline Latino or Latina $\times$ time & & & & -0.069 & 0.243 & 0.933 \\
\hline Political views $\times$ time & & & & 0.079 & 0.039 & 1.082 \\
\hline Father's education $\times$ time & & & & -0.004 & 0.019 & 0.996 \\
\hline Mother's education $\times$ time & & & & 0.025 & 0.020 & 1.025 \\
\hline Family income $\times$ time & & & & -0.044 & 0.025 & 0.957 \\
\hline Father's career: STEM $\times$ Time & & & & 0.000 & 0.067 & 1.000 \\
\hline Mother's career: $S T E M \times$ time & & & & 0.005 & 0.081 & 1.005 \\
\hline High school GPA $\times$ time & & & & -0.011 & 0.030 & 0.990 \\
\hline Self-rating: Math ability $\times$ time & & & & 0.052 & 0.041 & 1.053 \\
\hline Leader $($ factor $) \times$ time & & & & \multicolumn{3}{|c|}{ Not significant in step 0 model } \\
\hline Scholar $($ factor $) \times$ time & & & & -0.032 & 0.038 & 0.968 \\
\hline Future Act: Change major field $\times$ time & & & & -0.048 & 0.033 & 0.953 \\
\hline Future Act: Make ' $B$ ' average $\times$ time & & & & 0.056 & 0.057 & 1.058 \\
\hline Goal: Meaningful philosophy $\times$ time & & & & 0.001 & 0.033 & 1.001 \\
\hline Goal: Theoretical scientific contrib. $\times$ time & & & & -0.060 & 0.033 & 0.942 \\
\hline Goal: Raising a family $\times$ time & & & & -0.022 & 0.030 & 0.978 \\
\hline Social activist $($ factor $) \times$ time & & & & -0.013 & 0.036 & 0.987 \\
\hline Artistic $($ factor $) \times$ time & & & & 0.031 & 0.032 & 1.032 \\
\hline Status striver $($ factor $) \times$ time & & & & -0.045 & 0.036 & 0.956 \\
\hline Educ. reasons for college $($ factor $) \times$ time & & & & -0.002 & 0.038 & 0.998 \\
\hline Extrin. reasons for college $($ factor $) \times$ time & & & & 0.016 & 0.027 & 1.016 \\
\hline Distance of institution from home $\times$ time & & & & 0.038 & 0.024 & 1.039 \\
\hline Number of institutions applied to $\times$ time & & & & -0.013 & 0.013 & 0.987 \\
\hline Financial concern for college $\times$ time & & & & -0.050 & 0.047 & 0.951 \\
\hline Student-to-faculty ratio $\times$ time & & & & -0.039 & 0.009 & 0.962 \\
\hline Institutional type: University $\times$ time & & & & 0.046 & 0.099 & 1.047 \\
\hline Institutional type: Religious $\times$ time & & & & 0.068 & 0.117 & 1.070 \\
\hline Institutional type: $H B C U \times$ time & & & & -0.072 & 0.365 & 0.930 \\
\hline Institutional control: Public $\times$ time & & & & 0.271 & 0.100 & 1.312 \\
\hline Ph.D. $\times$ time & & & & -0.136 & 0.109 & 0.873 \\
\hline Law $\times$ time & & & & 0.204 & 0.268 & 1.226 \\
\hline Medical degree $\times$ time & & & & -0.113 & 0.138 & 0.893 \\
\hline Master's degree or M.Div. $\times$ time & & & & 0.054 & 0.108 & 1.055 \\
\hline
\end{tabular}

women to major in physics might simply be the same as the characteristics leading them to any STEM field. Thus, the last part of our analysis sought to differentiate women physics majors from women pursuing other STEM fields (biological sciences, chemistry, computer science, engineering, and math). These results are presented in Table IV and follow the same organization as presented previously in Table III.
A comparison of Tables III and IV reveals that nearly every variable that distinguished female physics majors from all other majors also distinguished female physics majors from women pursuing other STEM fields. For example, traits such as having confidence in one's math ability, desiring to make a theoretical contribution to science, having weaker social activist orientation, and attending college for educational (rather than extrinsic) 
TABLE IV. Logistic regression predicting choice of physics major among women (compared to other STEM majors) $(n=65993)$. Bold indicates $p<0.01$.

\begin{tabular}{|c|c|c|c|c|c|c|}
\hline \multirow[b]{2}{*}{ Variables } & \multicolumn{3}{|c|}{ Main effects model } & \multicolumn{3}{|c|}{ Conditional effects model } \\
\hline & $b$ & SE & $\operatorname{Exp}(B)$ & $b$ & SE & $\operatorname{Exp}(B)$ \\
\hline Year (continuous) & 0.087 & 0.033 & 1.091 & 0.266 & 0.440 & 1.305 \\
\hline \multicolumn{7}{|c|}{ Personal inputs } \\
\hline \multicolumn{7}{|l|}{ Religion (versus Protestant) } \\
\hline Catholic & -0.079 & 0.083 & 0.924 & -0.191 & 0.226 & 0.826 \\
\hline Jewish & -0.176 & 0.174 & 0.838 & -0.752 & 0.484 & 0.471 \\
\hline Other & 0.268 & 0.119 & 1.307 & 0.406 & 0.339 & 1.501 \\
\hline No religion & 0.233 & 0.085 & 1.263 & 0.425 & 0.240 & 1.530 \\
\hline \multicolumn{7}{|l|}{ Race (versus White) } \\
\hline Other or multi & 0.080 & 0.118 & 1.083 & -0.154 & 0.438 & 0.857 \\
\hline Asian or Pacific Islander & -0.527 & 0.130 & 0.590 & -0.209 & 0.421 & 0.811 \\
\hline Black & -0.154 & 0.204 & 0.857 & -0.032 & 0.555 & 0.968 \\
\hline Latino or Latina & -0.161 & 0.221 & 0.852 & -0.028 & 0.822 & 0.973 \\
\hline Political views & -0.046 & 0.043 & 0.955 & -0.210 & 0.120 & 0.810 \\
\hline \multicolumn{7}{|c|}{ Background characteristics } \\
\hline Father's education & 0.024 & 0.021 & 1.025 & 0.072 & 0.056 & 1.075 \\
\hline Mother's education & -0.017 & 0.022 & 0.983 & -0.068 & 0.059 & 0.934 \\
\hline Family income & \multicolumn{6}{|c|}{ Not significant in step 0 model } \\
\hline Father's career: STEM & 0.029 & 0.072 & 1.029 & -0.014 & 0.204 & 0.986 \\
\hline Mother's career: STEM & \multicolumn{6}{|c|}{ Not significant in step 0 model } \\
\hline \multicolumn{7}{|c|}{ Learning experiences } \\
\hline High school GPA & -0.023 & 0.033 & 0.978 & 0.023 & 0.087 & 1.024 \\
\hline \multicolumn{7}{|c|}{ Self-efficacy } \\
\hline Self-rating: Math ability & 0.655 & 0.046 & 1.926 & 0.444 & 0.128 & 1.559 \\
\hline Leader (factor) & \multicolumn{6}{|c|}{ Not significant in step 0 model } \\
\hline Scholar (factor) & 0.019 & 0.042 & 1.019 & 0.105 & 0.118 & 1.111 \\
\hline \multicolumn{7}{|c|}{ Outcome expectations } \\
\hline Future act: Change major field & 0.337 & 0.039 & 1.401 & 0.460 & 0.108 & 1.584 \\
\hline Future act: Make at least a ' $\mathrm{B}$ ' average & 0.009 & 0.064 & 1.009 & -0.157 & 0.176 & 0.855 \\
\hline \multicolumn{7}{|c|}{ Interests } \\
\hline Goal: Meaningful philosophy & 0.125 & 0.036 & 1.133 & 0.114 & 0.103 & 1.121 \\
\hline Goal: Theoretical scientific contrib. & 0.665 & 0.040 & 1.944 & 0.923 & 0.115 & 2.517 \\
\hline Goal: Raising a family & -0.041 & 0.033 & 0.960 & 0.028 & 0.091 & 1.029 \\
\hline Social activist (factor) & -0.364 & 0.039 & 0.695 & -0.327 & 0.112 & 0.721 \\
\hline Artistic (factor) & 0.216 & 0.036 & 1.241 & 0.078 & 0.101 & 1.081 \\
\hline Status striver (factor) & -0.292 & 0.041 & 0.746 & -0.167 & 0.116 & 0.846 \\
\hline Educ. reasons for college (factor) & 0.120 & 0.043 & 1.128 & 0.143 & 0.119 & 1.154 \\
\hline Extrins. reasons for College (factor) & -0.151 & 0.030 & 0.860 & -0.185 & 0.085 & 0.831 \\
\hline \multicolumn{7}{|c|}{ Contextual influences proximal to choice behavior } \\
\hline Distance of institution from home & 0.024 & 0.027 & 1.025 & -0.050 & 0.071 & 0.951 \\
\hline Number of institutions applied to & 0.015 & 0.014 & 1.015 & 0.028 & 0.046 & 1.028 \\
\hline Financial concern for college & -0.069 & 0.050 & 0.933 & 0.003 & 0.136 & 1.003 \\
\hline Student-to-faculty ratio & $-\mathbf{0 . 0 3 8}$ & 0.010 & 0.962 & 0.059 & 0.027 & 1.060 \\
\hline Institutional type: University & -0.255 & 0.114 & 0.775 & -0.325 & 0.295 & 0.723 \\
\hline Institutional type: Religious & 0.008 & 0.134 & 1.008 & -0.230 & 0.358 & 0.795 \\
\hline Institutional type: HBCU & -0.920 & 0.426 & 0.399 & -0.581 & 1.058 & 0.559 \\
\hline Institutional control: Public & -0.140 & 0.116 & 0.870 & -0.840 & 0.310 & 0.432 \\
\hline \multicolumn{7}{|c|}{ Choice goals } \\
\hline \multicolumn{7}{|l|}{ Degree aspirations (versus BA) } \\
\hline Ph.D. & 0.815 & 0.127 & 2.259 & 1.183 & 0.320 & 3.265 \\
\hline Law degree & 0.717 & 0.292 & 2.049 & 0.593 & 0.880 & 1.809 \\
\hline
\end{tabular}


TABLE IV. (Continued)

\begin{tabular}{|c|c|c|c|c|c|c|}
\hline \multirow[b]{2}{*}{ Variables } & \multicolumn{3}{|c|}{ Main effects model } & \multicolumn{3}{|c|}{ Conditional effects model } \\
\hline & $b$ & $\mathrm{SE}$ & $\operatorname{Exp}(B)$ & $b$ & SE & $\operatorname{Exp}(B)$ \\
\hline Medical Degree & -0.723 & 0.156 & 0.485 & -0.495 & 0.397 & 0.610 \\
\hline Master's degree or M.Div. & 0.376 & 0.127 & 1.457 & 0.132 & 0.322 & 1.141 \\
\hline \multicolumn{7}{|c|}{ Interaction terms } \\
\hline Catholic $\times$ time & & & & 0.034 & 0.076 & 1.035 \\
\hline Jewish $\times$ time & & & & 0.182 & 0.152 & 1.200 \\
\hline Other $\times$ time & & & & -0.061 & 0.116 & 0.941 \\
\hline No religion $\times$ time & & & & -0.074 & 0.078 & 0.929 \\
\hline Other or multi $\times$ time & & & & 0.074 & 0.129 & 1.076 \\
\hline Asian or Pacific Islander $\times$ time & & & & -0.099 & 0.130 & 0.906 \\
\hline Black $\times$ time & & & & -0.049 & 0.186 & 0.952 \\
\hline Latino or Latina $\times$ time & & & & -0.031 & 0.241 & 0.969 \\
\hline Political views $\times$ time & & & & 0.057 & 0.039 & 1.059 \\
\hline Father's education $\times$ time & & & & -0.017 & 0.019 & 0.983 \\
\hline Mother's education $\times$ time & & & & 0.017 & 0.020 & 1.018 \\
\hline Family income $\times$ time & & & & \multicolumn{3}{|c|}{ Not significant in step 0 Model } \\
\hline Father's career: $S T E M \times$ time & & & & 0.015 & 0.066 & 1.016 \\
\hline Mother's career: $S T E M \times$ time & & & & \multicolumn{3}{|c|}{ Not significant in step 0 model } \\
\hline High school GPA $\times$ time & & & & -0.017 & 0.030 & 0.983 \\
\hline Self-rating: Math ability $\times$ time & & & & 0.075 & 0.042 & 1.077 \\
\hline Leader $($ factor $) \times$ time & & & & \multicolumn{3}{|c|}{ Not significant in step 0 model } \\
\hline Scholar $($ factor $) \times$ time & & & & -0.032 & 0.038 & 0.969 \\
\hline Future act: Change major field $\times$ time & & & & -0.043 & 0.036 & 0.958 \\
\hline Future act: Make ' $B$ ' average $\times$ time & & & & 0.055 & 0.058 & 1.056 \\
\hline Goal: meaningful philosophy $\times$ time & & & & 0.005 & 0.033 & 1.005 \\
\hline Goal: Theoretical scientific contrib. $\times$ time & & & & -0.089 & 0.037 & 0.914 \\
\hline Goal: Raising a family $\times$ time & & & & -0.022 & 0.030 & 0.978 \\
\hline Social activist $($ factor $) \times$ time & & & & -0.012 & 0.036 & 0.988 \\
\hline Artistic $($ factor $) \times$ time & & & & 0.046 & 0.033 & 1.047 \\
\hline Status striver $($ factor $) \times$ time & & & & -0.041 & 0.037 & 0.960 \\
\hline Educ. reasons for college $($ factor $) \times$ time & & & & -0.010 & 0.039 & 0.990 \\
\hline Extrin. reasons for college $($ factor $) \times$ time & & & & 0.011 & 0.027 & 1.011 \\
\hline Distance of institution from home $\times$ time & & & & 0.026 & 0.024 & 1.027 \\
\hline Number of institutions applied to $\times$ time & & & & -0.003 & 0.013 & 0.997 \\
\hline Financial concern for college $\times$ time & & & & -0.025 & 0.046 & 0.975 \\
\hline Student-to-faculty ratio $\times$ time & & & & -0.034 & 0.009 & 0.966 \\
\hline Institutional type: University $\times$ time & & & & 0.028 & 0.101 & 1.028 \\
\hline Institutional type: Religious $\times$ time & & & & 0.091 & 0.120 & 1.095 \\
\hline Institutional type: $H B C U \times$ time & & & & -0.135 & 0.382 & 0.874 \\
\hline Institutional control: Public $\times$ time & & & & 0.249 & 0.102 & 1.282 \\
\hline Ph.D. $\times$ time & & & & -0.135 & 0.109 & 0.874 \\
\hline Law $\times$ time & & & & 0.028 & 0.272 & 1.029 \\
\hline Medical Degree $\times$ time & & & & -0.087 & 0.134 & 0.917 \\
\hline Master's degree or M.Div. $\times$ time & & & & 0.076 & 0.110 & 1.079 \\
\hline
\end{tabular}

reasons not only differentiate female physics majors from all other majors, but they further distinguish female physics majors from women pursuing other STEM majors. Also, institutions with larger student-faculty ratios are increasingly less likely to attract physics majors relative to all other fields and relative to other STEM majors.

However, Table IV does reveal two additional traits that differentiate female physics majors from women in other
STEM fields. The first is that women aspiring to major in physics score higher on the artistic factor than their female counterparts in other STEM majors. Thus, women physics majors are more interested in creating artistic works and have higher ratings of their artistic ability than women who pursue other STEM fields. Second, women majoring in physics are less likely than their STEM-aspiring female counterparts to aspire to medical degrees, a finding which 
undoubtedly reflects the high representation of female STEM majors in the biological sciences. Both of these additional variables are stable predictors over time.

\section{LIMITATIONS}

While this study makes a contribution to the study of women in physics due to its reliance on national data, large collection of variables, and several-decade perspective, it nevertheless faces important limitations. First, the dependent variable only considers women's intention to major in physics at the point of college entry. Therefore, we are unable to address whether or not that intention actually leads to completion of a degree in physics.

A second limitation is that the study did not have access to all potential variables that may determine women's interest in physics majors. Because we were only able to consider survey items that were available in five different time points over four decades (and because the survey itself was constructed for broader topics than STEM major selection), structural factors such as gender-role socialization and certain experiences in $\mathrm{K}-12$ (such as physics coursework in high school) could not be considered.

Finally, these data reflect only first-time full-time students entering four-year colleges and universities and therefore do not capture any predictors of majoring in physics that may be unique to community college students. Future research will need to consider the characteristics that predict physics major aspirations among students who begin in community colleges.

\section{DISCUSSION AND IMPLICATIONS}

This paper considered the changing characteristics of female physics majors over the past four decades. The study found that interest among women in the physics major is low (hovering between $0.1 \%$ and $0.2 \%$ ) and is actually declining relative to their interest in certain other STEM majors (most notably biology and engineering). This finding supports the American Physical Society's [1] assertion that the sizable gender gap in the field of physics is due to a dearth of women choosing to pursue a physics major from the start. Hence, as administrators and educators seek to increase the number of women in physics, they should focus their efforts on recruitment initiatives. However, the field of physics should also begin to consider how it can change in order to attract a broader range of women. This research suggests that physics is recruiting a very narrow subpopulation of women who are significantly different than women in STEM and the female college population at large.

This study also revealed important shifts in the career aspirations of women who plan to major in physics. Research scientist is the most popular career choice but is declining in popularity, while increasing numbers of female physics majors say that they are undecided in their career plans. This finding may reflect that some women who plan to major in physics are unaware of the career options available to them. Hence, teachers, faculty, staff, and policymakers might work to educate women about the types of careers that a physics degree prepares students to pursue, including in health care and national defense. Raising awareness about the role of physics in health care may be particularly fruitful, given that previous research on the gender gap in STEM has found that women are more likely to pursue STEM fields that provide opportunities to help others $[28,29]$.

This study's findings further suggest that women who plan to major in physics are unique among their peers. That is, the predictors of women's choice of physics major indicated that there is a distinctive profile of the average female physics student as compared to all other women and women in other STEM fields, and for the most part this profile has remained consistent over the years. Women who intend to major in physics tend to be confident in their math abilities, value college as an opportunity to learn, plan to attend graduate school, and desire to make theoretical contributions to science. Further, the field consistently attracts women who place less value on social activist goals, a finding supported by the broader literature $[49,50]$.

If the field of physics wishes to attract more women, it may be necessary to change the perception of the field and the focus of the major in order to reach a broader audience. Whitten [51] has suggested various ways to make physics more attractive to a wider array of women, such as promoting physics research that situates physics in social and political problems, applying physics to human issues, and developing projects that focus on improving education. Considering that our research demonstrated that physics consistently attracts a particular type of female student, a rebranding of the field as suggested by Whitten [51] may be warranted. In other words, changes may be necessary in the academic and professional culture of physics in order to recruit more women, rather than women being pressured to adapt themselves in order to "fit" within physics.

Future research and educational efforts should take this perspective into account by taking a closer look at how women in physics may be different from women in higher education overall and how their experiences shape their choices and values. For example, scholarship by Danielsson [45] explores how the field of physics is constructed in a masculine domain, which contributes to women's low interest in the field. Additionally, future research could draw from Whitten's [51] recommendations to examine how physics programs can be structured to be of greater interest and professional relevance to women. Such research could explore the ways in which undergraduate physics courses and research projects emphasize social issues or employ problem-solving skills that can be transferred to a broad range of careers. 


\section{CONCLUSION}

This study used data from the CIRP Freshman Survey from 1971 through 2013. These data were explored using descriptive and inferential statistics to address three main questions. First, we analyzed the data to determine how women's interest in pursuing the physics major has changed in recent decades. Second, we considered how the career interests of women who plan to major in physics differ from career choices of women pursuing other fields, and how this has changed over time. Finally, we explored the traits of women who intend to major in physics and whether the salience of these characteristics has changed over the past four decades.

This paper contributes to the extant literature on women in physics in myriad ways. First, the findings from this study lend support and add to previous findings with the benefit of national, representative data over a long period of time. Further, this study's findings offer direction to scholars, administrators, and policymakers to focus their efforts on recruitment initiatives, particularly given the evolving nature of women's interest in physics and their interest in careers related to physics (e.g., research scientist). Finally, this study revealed a set of characteristics that increase the likelihood that a woman will pursue physics. Knowledge about these characteristics can guide recruitment efforts such that they can be targeted toward women who may be the best fit for a physics major and career; however, such efforts should also be mindful of how the field might evolve to attract a broader range of women.

\section{ACKNOWLEDGMENTS}

This research is supported by the National Science Foundation, HRD No. 1135727. Part of this work was also completed with the support of a Fulbright Fellowship in Finland.

\section{APPENDIX A: ITEMS INCLUDED IN REGRESSION MODELS}

\begin{tabular}{|c|c|}
\hline \multicolumn{2}{|l|}{ Variable list and coding } \\
\hline \multicolumn{2}{|l|}{ Dependent variable } \\
\hline Intent to major in engineering & Dichotomous: $0=$ All others, $1=$ Engineering \\
\hline \multicolumn{2}{|l|}{ Personal inputs } \\
\hline \multicolumn{2}{|l|}{ Religion (versus Protestant) } \\
\hline Catholic & Dichotomous: $0=$ "No", $1=$ "Yes" \\
\hline Jewish & Dichotomous: $0=$ "No", $1=$ "Yes" \\
\hline Other & Dichotomous: $0=$ "No", $1=$ "Yes" \\
\hline None & Dichotomous: $0=$ "No", $1=$ "Yes" \\
\hline \multicolumn{2}{|l|}{ Race (versus White) } \\
\hline African American & Dichotomous: $0=$ "No", $1=$ "Yes" \\
\hline Asian American & Dichotomous: $0=$ "No", $1=$ "Yes" \\
\hline Latino or Chicano & Dichotomous: $0=$ "No", $1=$ "Yes" \\
\hline Native American & Dichotomous: $0=$ "No", $1=$ "Yes" \\
\hline Political orientation & 5 -point scale: $1=$ "Far right" to $5=$ "Far left" \\
\hline \multicolumn{2}{|l|}{ Background characteristics } \\
\hline Father's education & 8-point scale: $1=$ "Grammar school or less" to $8=$ "Graduate degree" \\
\hline Mother's education & 8 -point scale: $1=$ "Grammar school or less" to $8=$ "Graduate degree" \\
\hline Family income & 25 -point scale: $1=$ "less than $6000 "$ to $25=$ "250 000 or more" \\
\hline Father's career: STEM & Dichotomous: $0="$ No", $1=$ "Yes" \\
\hline Mother's career: STEM & Dichotomous: $0=$ "No", $1=$ "Yes" \\
\hline \multicolumn{2}{|l|}{ Learning experiences } \\
\hline High school GPA (average grade in H.S.) & 8-point scale: $1=$ "D" to $8=$ "A or $\mathrm{A}+"$ \\
\hline \multicolumn{2}{|l|}{ Self-efficacy } \\
\hline Self-rated mathematical ability & 5 -point scale: $1=$ "Lowest $10 \% "$ to $5=$ "Highest $10 \% "$ \\
\hline Leader personality factor & See Appendix B \\
\hline Scholar personality factor & See Appendix B \\
\hline \multicolumn{2}{|l|}{ Outcome expectations } \\
\hline Future activity: Change major field & 4-point scale: $1=$ "No chance" to $4=$ "Very good chance" \\
\hline Future activity: Make at least a ' $\mathrm{B}$ ' average & 4-point scale: $1=$ "No chance" to $4=$ "Very good chance" \\
\hline
\end{tabular}

(Table continued) 
(Continued)

Variable list and coding

\section{Interests}

Goal: Develop a meaningful philosophy of life

Goal: Make a theoretical contribution. to science

Goal: Raise a family

Social activist personality factor

Artistic personality factor

Variable list and coding (continued)

Status striver personality factor

Education reasons for choosing a college factor

Extrinsic reasons for choosing a college factor

Contextual influences proximal to choice behavior

Distance from home

Number of institutions applied

Concern about finances

Student-faculty ratio

Institutional type: University or College

Institutional type: Religious or Nonsectarian

Institutional type: $\mathrm{HBCU}$

Control: Public or private

Choice goals

Degree aspirations (versus Bachelor's or less)

Ph.D.

Law

Medical degree

Master's degree or M.Div.

4-point scale: $1=$ "Not important" to $4=$ "Essential"

4-point scale: $1=$ "Not important" to $4=$ "Essential"

4-point scale: $1=$ "Not important" to $4=$ "Essential"

See Appendix B

See Appendix B

See Appendix B

See Appendix B

See Appendix B

5-point scale: $1=$ "10 miles or less" to $5=$ "More than 500 miles" 5-point scale: $1=$ "None" to $5=$ "Four or more"

3-point scale: 1 = "None", 2 ="Some", 3 ="major"

Dichotomous: $0=$ College, $1=$ University

Dichotomous: $0=$ Nonsectarian, $1=$ Religious

Dichotomous: $0=$ Non-HBCU, $1=\mathrm{HBCU}$

Dichotomous: $0=$ Private, $1=$ Public

Dichotomous: $0=$ All Others, $1=$ Ph.D.

Dichotomous: $0=$ All Others, $1=$ Law

Dichotomous: $0=$ All Others, $1=$ Medical

Dichotomous: $0=$ All Others, $1=$ Master's or M.Div.

\section{APPENDIX B: FACTOR ITEMS}

Factor variables, loadings, and reliabilities

Factor Factor loading

Leader personality

Self-rating: Drive to achieve ${ }^{a}$

$\alpha=0.65$

Self-rating: Leadership ability ${ }^{\text {a }}$

0.71

Self-rating: Self-confidence (social) ${ }^{\mathrm{a}}$

0.83

0.75

Scholar personality

$\alpha=0.64$

Self-rated: Academic ability ${ }^{\mathrm{a}}$

0.79

Self-rated: Self-confidence (intellectual) ${ }^{\mathrm{a}}$

0.78

Self-rated: Writing ability ${ }^{a}$

0.73

Social activist personality

$\alpha=0.72$

Goal: Influence social values ${ }^{\mathrm{b}}$

0.74

Goal: Participate in a community action program ${ }^{\mathrm{b}} \quad 0.75$

Goal: Help others in difficulty ${ }^{\mathrm{b}}$

0.61

0.69

Goal: Influence the political structure

0.64

Artistic personality

$\alpha=0.69$

Goal: Create artistic work ${ }^{\mathrm{b}}$

0.82

0.72

0.67

0.66

Goal: Write original works ${ }^{b}$

0.78

Status striver personality

0.64

Goal: Be very well-off financially ${ }^{b}$ 
(Continued)

Factor variables, loadings, and reliabilities

Factor

Factor loading

Goal: Become authority in my field ${ }^{\mathrm{b}}$

0.74

Goal: Be successful in a business of my own ${ }^{\mathrm{b}}$

0.62

Education reasons for choosing college

Reason: To gain a general education and appreciation of ideas ${ }^{c}$

$\alpha=0.60$

0.76

Reason: To make me a more cultured person ${ }^{\mathrm{c}}$

0.77

Reason: Learn more about things that interest $\mathrm{me}^{\mathrm{c}}$

0.73

Extrinsic reasons for choosing college

$\alpha=0.66$

0.86

Reason: To be able to get a better job ${ }^{\mathrm{c}}$

0.86

"Five-point scale: 1 = "lowest $10 \% "$ to 5 = "highest 10\%".

"Four-point scale: $1=$ "not important" to $4=$ "essential".

"Three-point scale: $1=$ "not important" to $3=$ "very important".

[1] Gender equity: Strengthening the physics enterprise in universities and national laboratories, American Physics Society Report, 2007, https://www.aps.org/programs/ women/workshops/gender-equity/upload/genderequity.pdf.

[2] S. White and C. Tesfaye, Female Students in High School Physics (American Institute of Physics, College Park, MD, 2011).

[3] Fraction of bachelor's degrees earned by women, https://www .aps.org/programs/education/statistics/womenmajors.cfm.

[4] Digest of Education Statistics (National Center for Education Statistics, Washington, DC, 2013).

[5] R. Ivie, S. White, A. Garrett, and G. Anderson, Women among physics and astronomy faculty, https://www.aip.org/ sites/default/files/statistics/faculty/womenfac-pa-10.pdf.

[6] A. M. Kanny, L. J. Sax, and T. A. Riggers-Piehl, Investigating forty years of STEM research: How explanations for the gender gap have evolved over time, J. Women Minorities Sci. Eng. 20, 127 (2014).

[7] G. Huang, N. Taddese, and E. Walter, Entry and Persistence of Women and Minorities in College Science and Engineering Education (National Center for Education Statistics, Washington, DC, 2000).

[8] E. Seymour and N. M. Hewitt, Talking About Leaving: Why Undergraduates Leave The Sciences (Westview Press, Boulder, CO, 1997).

[9] M. Ong, C. Wright, L. L. Espinosa, and G. Orfield, Inside the double bind: A synthesis of empirical research on undergraduate and graduate women of color in science, technology, engineering, and mathematics, Harv. Educ. Rev. 81, 172 (2011).

[10] J. Burrelli, in Proceedings of the CEOSE Mini-Symposium on Women of Color in STEM, 2009 (National Science Foundation, Arlington, VA, 2009).
[11] H.S. Astin and L.J. Sax, in The Equity Equation: Fostering the Advancement of Women in the Sciences, Mathematics, and Engineering, edited by C. Davis, A. B. Ginorio, C. S. Hollenshead, B. B. Lazarus, and P. M. Rayman (Jossey-Bass, San Francisco, 1996).

[12] B. M. Vetter, in The Equity Equation: Fostering the Advancement of Women in the Sciences, Mathematics, and Engineering (Ref. [11]).

[13] P. R. Aschbacher, E. Li, and E. J. Roth, Is science me? High school students' identities, participation and aspirations in science, engineering, and medicine, J. Res. Sci. Teach. 47, 5 (2010).

[14] M. Wang and J. Degol, Motivational pathways to STEM career choices: Using expectancy-value perspective to understand individual and gender differences in STEM fields, Dev. Pol. Rev. 33, 304 (2013).

[15] E. A. Gunderson, G. Ramirez, S. C. Levine, and S. L. Beilock, The role of parents and teachers in the development of gender-related math attitudes, Sex Roles 66, 153 (2012).

[16] H. R. Tenenbaum and C. Leaper, Parent-child conversations about science: The socialization of gender inequities?, Dev. Psychol. 39, 34 (2003).

[17] P. M. Frome and J.S. Eccles, Parents' influence on children's achievement-related perceptions, J. Pers. Soc. Psychol. 74, 435 (1998).

[18] J. C. Blickenstaff, Women and science careers, Gender Educ. 17, 369 (2005)

[19] J. Kinzie, Women's paths in science: A critical feminist analysis, New Dir. Inst. Res. 2007, 81 (2007).

[20] P. M. Huang and S. G. Brainard, Identifying determinants of academic self-confidence among science, math, engineering, and technology students, J. Women Minorities Sci. Eng. 7, 315 (2001). 
[21] J. Jovanovic and S.S. King, Boys and girls in the performance-based science classroom: Who's doing the performing?, Am. Educ. Res. J. 35, 477 (1998).

[22] J. S. Eccles and J.E. Jacobs, Social forces shape math attitudes and performance, Signs (The University of Chicago Press, Chicago, 1986), Vol. 11, pp. 367-380.

[23] L. J. Sax, Retaining tomorrow's scientists: Exploring the factors that keep male and female college students interested in science careers, J. Women Minorities Sci. Eng. 1, 45 (1994).

[24] L. J. Sax, The Gender Gap in College: Maximizing the Developmental Potential of Women and Men (Jossey-Bass, San Francisco, 2008).

[25] F. Pajares, Gender Differences in Mathematics: An Integrative Psychological Approach (Cambridge University Press, Cambridge, England, 2005).

[26] S. F. Chipman, D. H. Krantz, and R. Silver, Mathematics anxiety and science careers among able college women, Psychol. Sci. 3, 292 (1992).

[27] L. J. Sax, J. A. Jacobs, and T. A. Riggers, Women's Representation in Science and Technology (STEM) Fields of Study, 1976-2006, Paper presented at the annual meeting of the Association for the Study of Higher Education (ASHE), November 2010, Indianapolis, Indiana (2010).

[28] J. J. Thompson and M. A. Windschitl, in Proceedings of the Annual Meeting of the American Education Research Association, New Orleans, LA, 2002.

[29] L. J. Sax, Undergraduate science majors: Gender differences in who goes to graduate school, Rev. High. Educ. 24, 153 (2001).

[30] J. Margolis and A. Fisher, Unlocking the Clubhouse: Women in Computing (The MIT Press, Cambridge, MA, 2002).

[31] S. Cheryan, J. O. Siy, M. Vichayapai, B. J. Drury, and S. Kim, Do female and male role models who embody STEM stereotypes hinder women's anticipated success in STEM?, Soc. Psychol. Pers. Sci. 2, 656 (2011).

[32] A. B. Diekman, E. R. Brown, A. M. Johnston, and E. K. Clark, Seeking congruity between goals and roles: A new look at why women opt out of science, technology, engineering, and mathematics careers, Psychol. Sci. 21, 1051 (2010).

[33] A. B. Diekman, E. K. Clark, A. M. Johnston, E. R. Brown, and M. Steinberg, Malleability in communal goals and beliefs influences attraction to STEM careers: Evidence for a goal congruity perspective, J. Pers. Soc. Psychol. 101, 902 (2011).

[34] H. B. Carlone, (Re)producing good science students: Girls' participation in high school physics, J. Women Minorities Sci. Eng. 9, 17 (2003).

[35] Z. Hazari, G. Sonnert, P. M. Sadler, and M. Shanahan, Connecting high school physics experiences, outcome expectations, physics identity, and physics career choice, J. Res. Sci. Teach. 47, 978 (2010).
[36] Z. Hazari, R. H. Tai, and P. M. Sadler, Gender differences in introductory university physics performance: The influence of high school physics preparation and affective factors, Sci. Educ. 91, 847 (2007).

[37] P. M. Sadler and R. H. Tai, Success in introductory college physics: The role of high school preparation, Sci. Educ. 85, 111 (2001).

[38] R. Trumper, Factors affecting junior high school students' interest in physics, J. Sci. Educ. Technol. 15, 47 (2006).

[39] R. W. Lent, S. D. Brown, and G. Hackett, Toward a unifying social cognitive theory of career and academic interest, choice, and performance, J. Vocat. Behav. 45, 79 (1994).

[40] R. W. Lent et al., Social cognitive predictors of academic interests and goals in engineering: Utility for women and students at historically black universities, J. Counsel. Psychol. 52, 84 (2005).

[41] A. Traxler, X. Xid, J. Blue, and R. Barthelemy, Enriching gender in PER: A binary past and complex future (to be published).

[42] R. Barthelemy, M. McCormick, and C. Henderson, Barriers beyond equity: An exploratory study of women graduate students' career pathways in astronomy, Int. J. Gender Sci. Technol. 7, 1 (2015).

[43] M. McCormick, R. Barthelemy, and C. Henderson, Women's persistence into graduate astronomy programs: The roles of support, interest, and capital, J. Women Minorities Sci. Eng. 20, 317 (2014).

[44] A. J. Gonsalves, in Doctoral Education: Research-Based Strategies for Doctoral Students, Supervisors, and Administrators, edited by L. McAlpine and C. Amundsen (Springer, Dordrecht, 2011).

[45] A. T. Danielsson, Exploring woman university physics students "doing gender" and "doing physics,", Gender Educ. 24, 25 (2012).

[46] J. H. Pryor, S. Hurtado, V. B. Saenz, J. L. Santos, and W. S. Korn, The American Freshman: Forty Year Trends (Higher Education Research Institute, Los Angeles, 2007).

[47] A. W. Astin, What Matters in College? Four Critical Years Revisited (Jossey-Bass, San Francisco, 1993), Vol. 1.

[48] L. J. Sax, The Gender Gap in College: Maximizing the Developmental Potential of Women and Men (Jossey-Bass, San Francisco, 2008).

[49] Z. Hazari, G. Potvin, R. H. Tai, and J. T. Almarode, Motivation toward a graduate career in the physical sciences: Gender differences and the impact on science career productivity, J. Coll. Sci. Teach. 41, 90 (2012).

[50] J.S. Eccles, in Why Aren't More Women in Science?, edited by S. J. Ceci and W. M. Williams (American Psychological Association, Washington, DC, 2007).

[51] B.L. Whitten, (Baby) steps toward feminist physics, J. Women Minorities Sci. Eng. 18, 115 (2012). 